\title{
Brote de COVID-19 en la comunidad nativa Palma Real, Madre de Dios, Perú
}

\section{Outbreak of COVID-19 in the Palma Real native community, Madre de Dios, Peru}

\author{
Jesús Rojas-Jaimes ${ }^{1,2, a}$, German Correa Nuñez ${ }^{3, b}$, Carlos Peralta Siesquen ${ }^{4, c}$, Daniel Valdez Puma, \\ David Cayulla Quispe \\ ${ }^{1}$ Facultad de Ciencias de la Salud, Universidad Privada del Norte. Lima, Perú. \\ ${ }^{2}$ Escuela de Medicina Humana, Univesidad Científica del Sur. Lima, Perú. \\ ${ }^{3}$ Departamento Académico de Ciencias Básicas, Universidad Amazónica de Madre de Dios. Madre de Dios, Perú. \\ ${ }^{4}$ Redes de Salud Periféricas, Gobierno Regional de Madre de Dios. Madre de Dios, Perú. \\ ${ }^{5}$ Hospital Santa Rosa. Madre de Dios, Perú. \\ ${ }^{a}$ Maestro en biologia molecular, ORCID: https://orcid.org/0000-0002-6910-9341 \\ ${ }^{b}$ Doctor en ciencias de la salud, ORCID: https://orcid.org/0000-0002-4896-8120 \\ ${ }^{\circ}$ Microbiólogo, ORCID: https://orcid.org/0000-0001-8668-2724 \\ ${ }^{d}$ Médico, ORCID: https://orcid.org/0000-0002-9827-0468 \\ ${ }^{e}$ Parasitólogo, ORCID: https://orcid.org/0000-0001-8208-8947
}

An Fac med. 2021;82(3):239-41. / DOI: https://doi.org/10.15381/anales.v82i3.21561

Correspondencia:
Jesús Rojas Jaimes
jesus.rojas.jaimes@gmail.com

Recibido: 2 de septiembre 2021 Aprobado: 8 de noviembre 2021 Publicación en línea: 16 de noviembre 2021

Conflictos de interés: Los autores declaran no tener conflictos de interés.

Fuente de financiamiento: Autofinanciado

Citar como: Rojas-Jaimes J, Correa G, Peralta C, Valdez D, Cayulla D. Brote de COVID-19 en la comunidad nativa Palma Real, Madre de Dios, Perú. An Fac med. 2021;82(3):239-41. DOI: https://doi.org/10.15381/anales. v82i3.21561
Sr. Editor,

En diciembre del 2019 en la ciudad de Wuhan, provincia de Hubei en China, se presentó un grupo de neumonías atípicas, que luego las investigaciones epidemiológicas mostraron que la mayoría de pacientes estaban relacionados al haber concurrido a un "mercado húmedo", centro de comercialización de alimentos basados en carne de animales, con una extraña enfermedad, pudiendo identificar el agente causal como el SARS-CoV-2 siendo la enfermedad Ilamada COVID-19 (1).

La pandemia de la COVID-19 se ha extendido incluso a la Amazonía, con su clima cálido y húmedo, precipitaciones hasta de 8 meses al año, y un verano intenso de cuatro meses, que no serían condiciones idóneas para que se presente la COVID-19 ${ }^{(2)}$ lo que lleva a considerar cómo afectaría a los pueblos originarios amazónicos. El pueblo indígena originario de los Eseeja comparte comunidades entre Bolivia y Perú, correspondiendo al Perú tres comunidades: Infierno (en el río Tambopata), Palma Real (en el río Bajo Madre de Dios), y Sonene (en el río Sonene, frontera natural con Bolivia). Se reporta que los Ese eja no se relacionen directamente con foráneos, y en el caso de tener que hacerlo, lo hacen con mucha cautela ${ }^{(3)}$.

Reportamos el caso del brote por COVID-19 en la comunidad indígena Ese eja en Palma Real-Madre de Dios en junio del año 2020. Se obtuvieron los datos epidemiológicos y sociodemográficos de los pacientes con sintomatología incluyendo el caso cero y los contactos. Seguidamente se tomaron las pruebas de hisopado nasofaríngeo para los diagnósticos moleculares por RT-PCR para la identificación del SARS-CoV-2, las muestras fueron llevadas en cadena de frio al Instituto Nacional de Salud del Perú. Además, se procesaron muestras serológicas para la identificación de IgM e IgG en personas con síntomas y contactos. Se realizaron estadísticas descriptivas sociodemográficas y de caracterización clínica, así también se hallo la tasa de ataque con un IC al 95\%. Se garantizó la confidencialidad de los datos obtenidos. 
Se encontraron 64 personas sintomáticas, 54 de ellas presentaban entre 1 a 4 días de inicio de síntomas respiratorios. De las 54 personas con síntomas sólo se realizaron 18 hisopados orofaríngeos y nasofaríngeos para las pruebas moleculares (por disponibilidad de recursos) y 44 pruebas rápidas (serológicas), realizando una intervención de contención por aislamiento y uso de medidas de bioseguridad como uso de mascarillas y lavado de manos. De las 18 pruebas moleculares, 17 (94,44\%) fueron positivas; y de las 44 pruebas serológicas, todas fueron positivas $(\lg M=17, \lg G$ e $\lg M=12, \lg G=15)$. Por falta de materiales a 2 personas no se les realizó pruebas confirmatorias.

Las características epidemiológicas relevantes fueron que los sintomáticos estuvieron con una edad media de 45,24 años, con 4,59 días en promedio de clínica y una tasa de ataque con IC del 95\% $=2,43 \%$ (tabla 1). Entre los síntomas mas

Tabla 1. Características epidemiológicas del brote de COVID-19 en la comunidad nativa de Palma Real, Madre de Dios, 2020, en personas positivas por RT-PCR.

$n=17$

\begin{tabular}{|c|c|c|}
\hline & $n=17$ & $\%$ \\
\hline \multicolumn{3}{|l|}{ Sexo } \\
\hline Femenino & 7 & $41,2 \%$ \\
\hline Masculino & 10 & $58,8 \%$ \\
\hline \multicolumn{3}{|l|}{ Viaje últimos 14 días } \\
\hline No & 12 & $70,6 \%$ \\
\hline $\mathrm{Si}$ & 5 & $29,4 \%$ \\
\hline \multicolumn{3}{|l|}{ Contacto confirmado } \\
\hline No & 15 & $88.2 \%$ \\
\hline $\mathrm{Si}$ & 2 & $11,8 \%$ \\
\hline \multicolumn{3}{|l|}{ Edad } \\
\hline Media & \multicolumn{2}{|c|}{45,24} \\
\hline Desviación estándar & \multicolumn{2}{|c|}{11,72} \\
\hline Mediana & \multicolumn{2}{|c|}{47,00} \\
\hline Rango & \multicolumn{2}{|c|}{21 a 64} \\
\hline \multicolumn{3}{|l|}{ Días de síntomas } \\
\hline Media & \multicolumn{2}{|c|}{4,59} \\
\hline Desviación estándar & \multicolumn{2}{|c|}{1.28} \\
\hline Mediana & \multicolumn{2}{|c|}{5} \\
\hline Rango & \multicolumn{2}{|c|}{3 a 7} \\
\hline Tasa de ataque & \multicolumn{2}{|c|}{$2,43 \%$} \\
\hline Estimación IC 95\% & \multicolumn{2}{|c|}{$2,43 \%(1,30 \%-3,50 \%)$} \\
\hline
\end{tabular}

prevalentes estuvieron la tos $(88,2 \%)$, fiebre y escalofrio $(82,4 \%)$ y cefalea $(82,4 \%) ;$ y entre las menos prevalentes, la dificultad respiratoria (5,9\%), dolor de pecho $(5,9 \%)$ y dolor de espalda $(5,9 \%)$, tal como se muestra en la figura 1.

En la comunidad nativa 17 personas presentaron prueba de RT-PCR positiva para COVID-19. De ellas, el 58,8\% fue de sexo masculino; el 29,4\% realizó un viaje en los últimos 14 días a la ciudad de Puerto Maldonado y el $11,8 \%$ (2 personas) tuvieron algún contacto confirmado para COVID-19. La edad media de las personas con un resultado de RT-PCR positivo fue de 45,24 años +/- 11,72 años, la edad mínima fue 21 años y la edad máxima fue 64 años. Las personas tuvieron una mediana de 5 días de haber iniciado con los síntomas, con un rango de 3 a 7 días. La tasa de ataque de COVID-19 en personas de 19 años a más fue del 2,43\%.
Los virus del tipo SARS son significativamente patógenos para los humanos y otros vertebrados, aunque las tasas de fatalidad varían dependiendo del país y la edad de la población desde 0,99 (Australia) a 17,95 (Francia) al 23 de Julio del $2020^{(4)}$. La tasa de ataque de $2,43 \%$ en el presente reporte indica que tres personas resultaron infectadas, confirmadas por la prueba molecular RT-PCR, de 100 personas expuestas en la comunidad. Según la literatura, los síntomas más comunes en los pacientes COVID 19 son: tos seca, diarrea, mialgia, dolor de cabeza y fiebre alta en un rango del $20 \%$ a $25 \%$ de los que no muestran signos de afectación respiratorio de la zona alta como estornudos y dolor de garganta ${ }^{(5)}$. En el presente estudio se reportó una similitud de 4 de los 5 síntomas como tos $(88,2 \%)$, dolor de cabeza $(82,4 \%)$, fiebre $(82,4 \%)$ y mialgia $(64,7 \%)$, siendo las tres primeras las más prevalentes.

Una de las barreras eficientes para prevenir la infección por SARS-CoV-2 es el uso de las barreras físicas como las mascarillas, lavado de manos y el uso de esto debe ser difundido por las autoridades con la finalidad que lleguen a los pueblos mas lejanos como las comunidades nativas ${ }^{(6)}$. En ese sentido en el momento de la intervención del brote se observó que, previo a los primeros casos no se empleaban las medidas de bioseguridad como el uso de las mascarillas.

La media de síntomas fue de 4,59 días. Según el seguimiento de casos la paciente que falleció comenzó sus síntomas al cuarto día del lugar probable de infección (Puerto Maldonado), y a los dos días siguientes en promedio comenzaron los síntomas en el resto de la población, infiriendo una alta carga viral y alta transmisión desde la paciente 0 a la población.

De otro lado, el haberse identificado por prueba serológica a 12 personas con IgG e IgM, y 15 personas con serología IgG, sugiere que la transmisión no habría sido reciente, sino habría ocurrido por lo menos desde más de dos semanas antes de reportado el caso sintomático que falleció (caso 1), por cuanto no se pudo identificar el "caso cero" (el primer infectado no necesariamente sintomático) (7), lo que lleva a considerar el hecho de que 


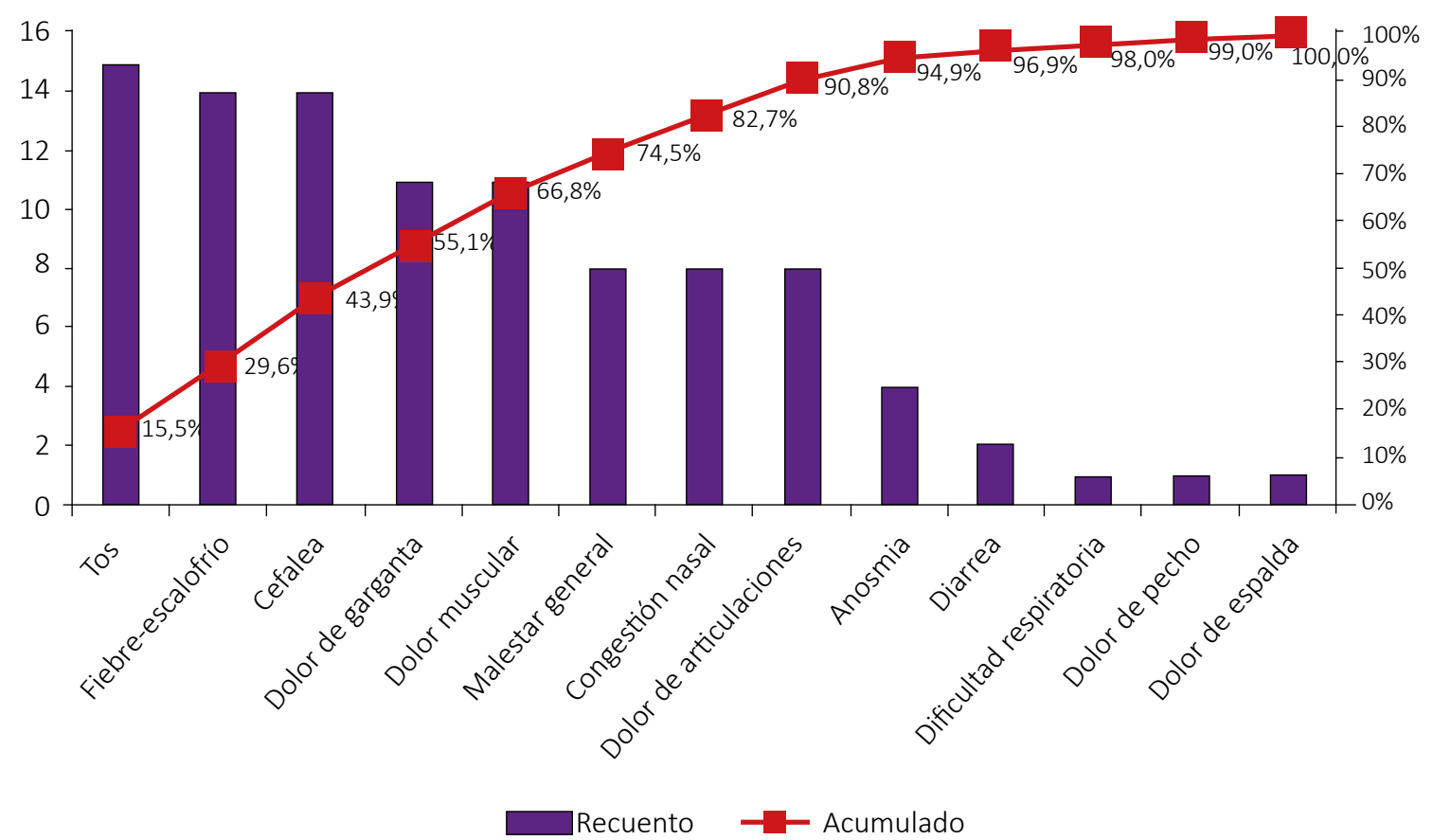

Figura 1. Distribución de síntomas asociados a COVID-19 en el brote de COVID-19 en la comunidad nativa de Palma Real, Madre de Dios, 2020.

la transmisión habría ocurrido crípticamente ${ }^{(8)}$ en la comunidad de Palma Real, hasta encontrar un paciente con comorbilidades (diabetes y obesidad) que llevó al sistema de salud a intervenir y establecer un sistema de vigilancia activa.

Agradecimientos. A Marco Espinola Sanchez por la elaboración de la tabla y figura.

\section{REFERENCIAS BIBLIOGRÁFICAS}

1. Huang C, Wang Y, Li X, Ren L, Zhao J, Hu Y, et al. Clinical features of patients infected with 2019 novel coronavirus in Wuhan, China. Lancet. 2020, 395, 497-506. DOI: 10.1016/S0140-6736(20)30183-5
2. Coelho Paraguassu E, Celis de Cardenas AM, Ferreira de Andrade R, La Vecchia C, B. Omer S, Naldi L, et al. The Covid-19 explosion in the state of Amapá: how is the most preserved region in the Brazilian Amazon currently fighting the SARSCOV 2 pandemic? Braz J Implantol Health Sci. 2020;2(5):3[11. DOI: https://doi.org/10.36557/26748169.2020v2n5p03-11

3. Adiseshan T. Humans as an essential part of the Amazon ecosystem: An analysis of land, plant, and game cultivation methods of the Kayapó and Ese eja [Internet]. 2010. Stanford.edu. [citado el 28 de enero del 2021]. Disponible en: https://socobilldurham.sites.stanford.edu/sites/g/files/sbiybj10241/f/ adiseshan_tara_amazon_2010_final_paper.pdf

4. World Health Organization [Internet]. Coronavirus Disease (COVID-19) Situation Report 121, Data as Received byWHO from National Authorities by 10:00 CEST. 20 May 2020. [Citado el 28 de enero del 2021] Viable en: https://www.who.int/docs/default-source/ coronaviruse/situation-reports/20200520-covid19-sitrep-121.pdf?sfvrsn=c4be2ec6_4

5. Li J-Y, You Z, Wang Q, Zhou Z-J, Qiu Y, Luo R, et al. The epidemic of 2019-novel-coronavirus (2019$\mathrm{nCoV}$ ) pneumonia and insights for emerging infectious diseases in the future. Microb. Infect. 2020; 22(1): 80-85. DOI: 10.1016/i.micinf.2020.02.002

6. Liu Y, Ning Z, Chen Y, et al. Aerodynamic analysis of SARS-CoV-2 in two Wuhan hospitals. Nature. 2020; 582 (1): 557-560. DOI: https://doi.org/10.1038/ s41586-020-2271-3

7. Carinci F. Covid-19: preparedness, decentralisation, and the hunt for patient zero. BMJ. 2020;368(1):1-2. DOI: 10.1136/bmj.m799

8. Bedford T, Greninger AL, Roychoudhury P, Starita LM, Famulare M, Huang M-L, et al. Cryptic transmission of SARS-CoV-2 in Washington state. Science. 2020:370(6516):571-5. DOI: 10.1126/science. abc0523 